\title{
Mathematical model of radial passive magnetic bearing
}

\author{
Leszek Matuszewski, Ph.D. \\ Gdansk University of Technology \\ Krzysztof Falkowski, Ph.D. \\ Military University of Technology, Warsaw
}

\section{ABSTRACT}

\begin{abstract}
In the article a mathematical model of radial passive magnetic bearings applicable to ocean engineering units has been presented. The application of the bearings in ship thrusters should increase durability of propulsion systems and give lower maintenance costs. The rotor of thruster's electric motor is suspended in magnetic field generated by radial passive magnetic bearings. However the maintaining of axial direction of the rotor must be controlled with electromagnets equipped with a high-dynamic controller. The risk of application of the magnetic bearings results from very low stiffness of the unit in comparison with rolling bearings. Also construction of the bearing should be different due to gyroscope effect and high forces generated during ship manoeuvring. The physical model performs correctly if electromagnets are controlled properly; and, technological problem with sealing system seems more significant than power supply to electromagnets winding. The equations presented in the article are necessary to build algorithms of a digital controller intended for on-line controlling magnetic bearing in axial direction.
\end{abstract}

Keywords: propeller, ring motor, magnetic bearing

\section{INTRODUCTION}

Possible application of magnetic bearings to ocean engineering units has been considered and tested for several years. Their low resistance to rolling and very long life time is of a great advantage. However because of a small stiffness they require introducing constructional changes into existing devices and new designed ones to be fitted with the so-called floating rotor. The bearing system presented in this paper is superior, as regards its durability, to traditional mechanical bearings both sliding and rolling ones. The most promising example of application of such bearing is the using it for ship main propulsion shaft line or thruster. In recent years fast development of engineering of polymer materials and their growing application to sea-water-lubricated slide bearings, has been observed. However the application of passive magnetic bearing of Halbach's configuration provides a comparably high stiffness of supporting, and simultaneously lack of wear-out phenomenon of interacting surfaces under operation.

The magnetic bearing is a device which makes use of repelling forces between homopolar magnets simultaneously placed in front to each other and coaxially, which keep rotor against stator in the state of levitation. Multi-row arrangement of magnetic rings provides a higher stiffness of bearing unit and more stable work in the neigbourhood of point of operation [1]. The levitation means keeping the rotor supported without any mechanical contact between it and stator. The main advantage of such bearings is elimination of friction forces between interacting elements. In the commonly used rolling and sliding bearings friction phenomena as such is not eliminated but only reduced. Moreover, in the traditional bearing systems

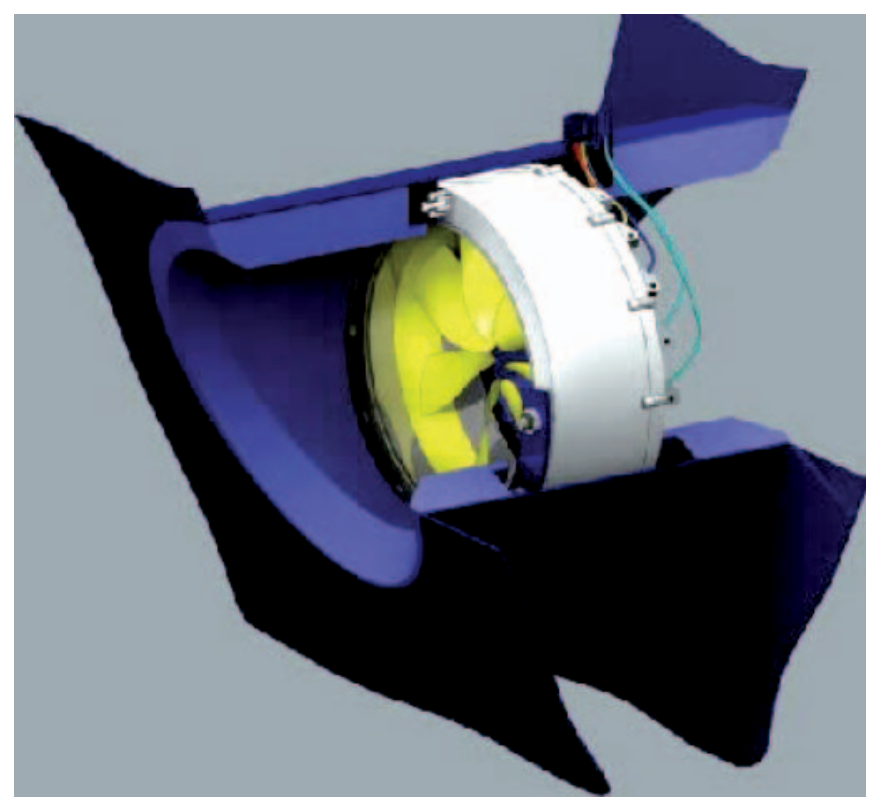

Fig. 1. Thruster based on a slip-ring motor

additional systems responsible for lubricating, cooling and discharging wear products are necessary. As results from the presented characteristics the application of classical bearings to operation in the environments more aggressive to materials or in a high vacuum meets significant difficulties and limitations. Therefore it is recommended, wherever justified, to apply magnetic suspensions which do not require additional systems, can operate in chemically active environments, and eliminate friction, extending this way life time of traditional bearings. 


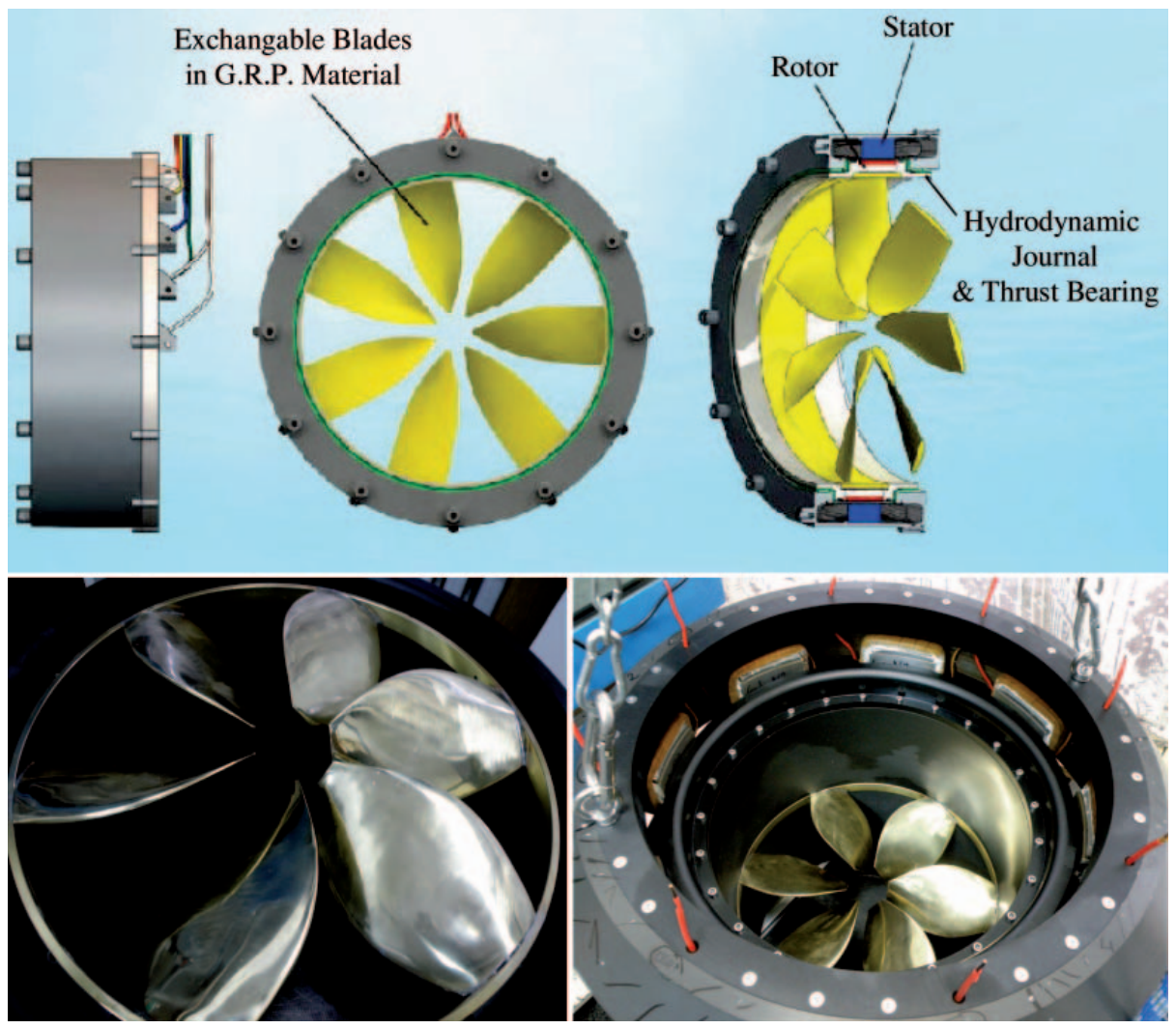

Fig. 2. Overall view of a Rim Drive device and the model intended for trials

Magnetic bearings are split in two basic groups: active and passive ones. The first group covers active bearings in which magnetic force value is proportional to position of rotor centre against hole centre and this way inversely proportional to value of a gap between interacting parts. In active bearing system the following items can be always found [3]:

- a sensor intended for the measuring of rotor position within air gap,

- a controller which transforms information on rotor position into steering signals,

- an amplifier which, on the basis of the steering signals, changes value of magnetic force by changing value of electric current flowing through active bearing coils in axial direction.

As results from the presented design of magnetic bearing, the rotor position stabilization is realized by the system of feedback between rotor position and magnetic force.

Passive magnetic bearings belong to the second group. In design of such bearings there is no feed-back system between rotor position within air gap and value of magnetic force. In design of passive bearings permanent magnets are used to produce magnetic forces [4].

The main advantage of passive bearings is its simple design, very high efficiency (as such bearings do not absorb energy during operation and provide simultaneously magnetic levitation) and relatively low cost. Nevertheless the lack of a feed-back system does not ensure a stable position of rotor around a given working point and does not make it possible to control its position within air gap. Active bearings are to be used in any case where a decisive condition is to maintain high precision in rotor positioning. Moreover it is not possible to build a fully isolated magnetic suspension system on the basis of only passive magnetic bearings (acc. Earnshaw theorem) [5]. Therefore in any solution of magnetically suspended rotor at least one actuator is to be active, and the remaining can be passive ones [6].
Hence for the bearing system of water propeller rotor it was proposed to apply two radial passive magnetic bearings and one axial active bearing. The bearing system is presented in Fig. 3.

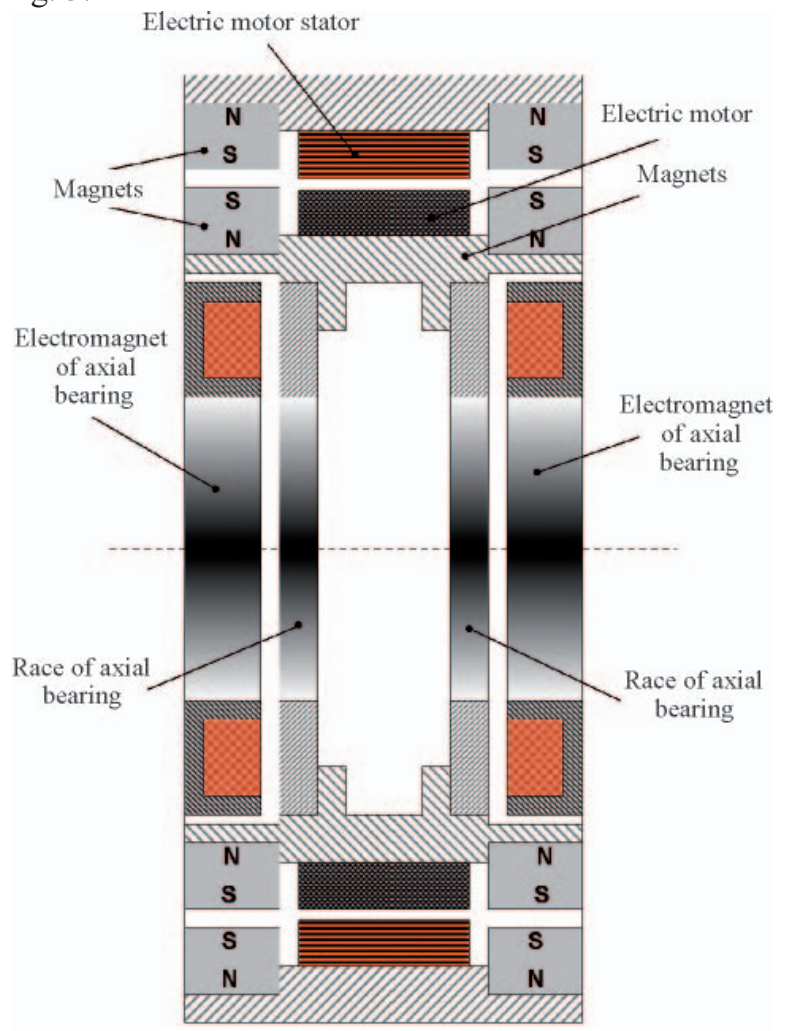

Fig. 3. Bearing system for water propeller rotor

In this paper a mathematical model of radial passive magnetic bearing is presented. Evaluation of the model is necessary to elaborate design algorithms for passive magnetic bearings. 


\section{PASSIVE MAGNETIC BEARING}

Two magnets or two sets of magnets are used to form a passive magnetic bearing [5]. In the simplest case two magnets repelling each other are used. One of them is rigidly connected with casing of rotary motor. It cannot displace. The other one is placed onto free rotor and can do, together with it, a complex motion being a sum of translational and rotational displacements. The moving magnet has six degrees of freedom and behaves as a magnetic compass needle which tries to be always lined up along external magnetic field lines (Fig. 4). As in the classical magnetic bearing there is a stator fixed in machine casing (motionless magnet) and a race placed in rotor (moving magnet). Between races of rolling bearing there are balls placed in bearing cage, and in slide bearing oil film appears between its races. In passive magnetic bearing a medium in which the bearing operates, is used. If a bearing operates in high vacuum conditions then between its races vacuum occurs, and a bearing immersed in water contains water between its races. This feature of magnetic bearing is one of its crucial merits. Obviously, apart from an environmental medium also magnetic field occurs between bearing stator and race.

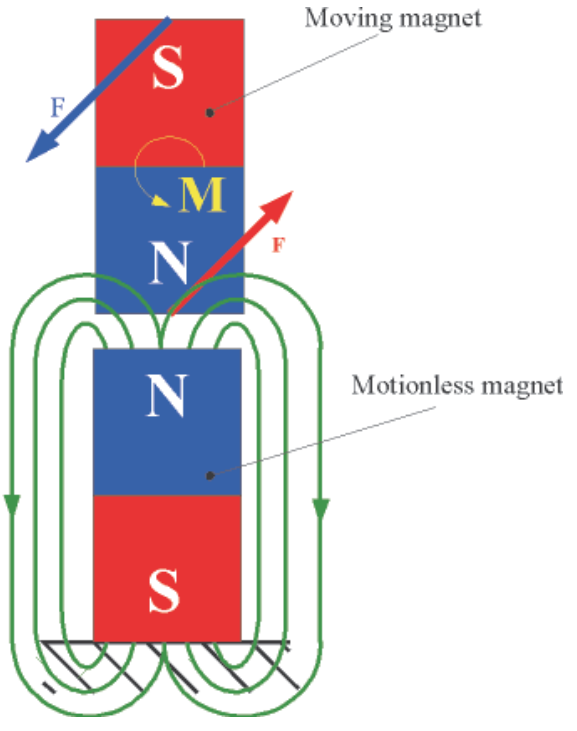

Fig. 4. Arrangement of magnets in repelling system
It can be assumed that in passive magnetic bearing the permanent magnet which does not displace is a source of non-uniform magnetic field. And, the permanent magnet connected with the rotor lines up along lines of external magnetic field generated by the magnet fixed in rotary machine casing [7].

As the magnet fixed in rotor behaves like a magnetic needle it tries to rotate its north pole towards south pole of the motionless magnet and shift its south pole so as to place it close to north pole of the motionless magnet. Magnet placed in a non-uniform magnetic field does a complex motion and its trajectory depends on initial position of moving magnet against that motionless. If magnets point to each other with opposite poles then they will try to be mutually connected. After connection the two magnets will behave as one magnet which becomes a magnetic dipole. If an orientation of the magnets is different from that above mentioned, then the magnet will rotate until they point to each other with opposite poles and then connect mutually. The connection of the magnets means that they reach state of equilibrium, hence such mutual position of the two magnets appears stable [7].

Any rotary displacement of rotor within magnetic bearing and mutual connection of its magnets would lead to a failure of rotary machine and its bearing. Only the maintaining of magnets in the position in which repelling forces between magnets occur, makes bearing work correct. The mutual repelling process of the magnets is a state of instable equilibrium, i.e. the state in which the system maintains its stability but with no stability margin.

The bearing intended for the transferring of radial loads consists of two magnets concentrically located (Fig. 5a). The bearing magnets are radially magnetized. The same magnetic pole takes place both on the outer circumference wall of the magnet fixed in machine rotor and on the inner circumference wall of the magnet fixed in machine casing. Such solution makes it possible to generate mutual repelling the magnets and this way magnetic levitation of the rotor to be suspended. As the manufacturing of uniform radially magnetized ring magnets is difficult, also bearings of rings built with segments, can be found. Such segment is a ring sector which is to be magnetized radially (Fig. 5b). Due to technological reasons it is not possible to produce an one-sided radial bearing. Radial bearings are always manufactured in a differential system. a)

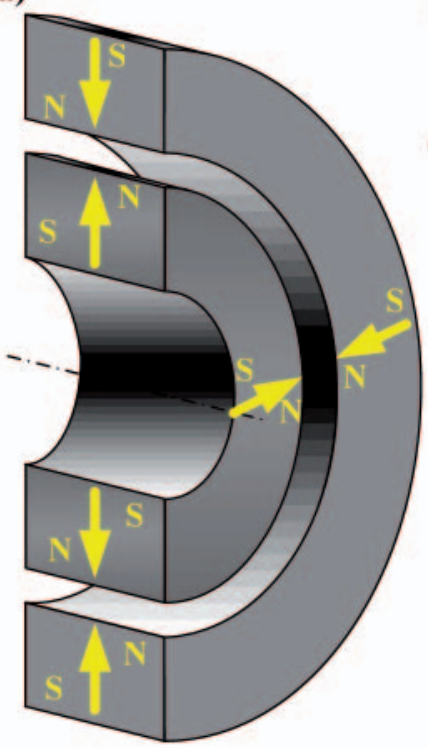

b)

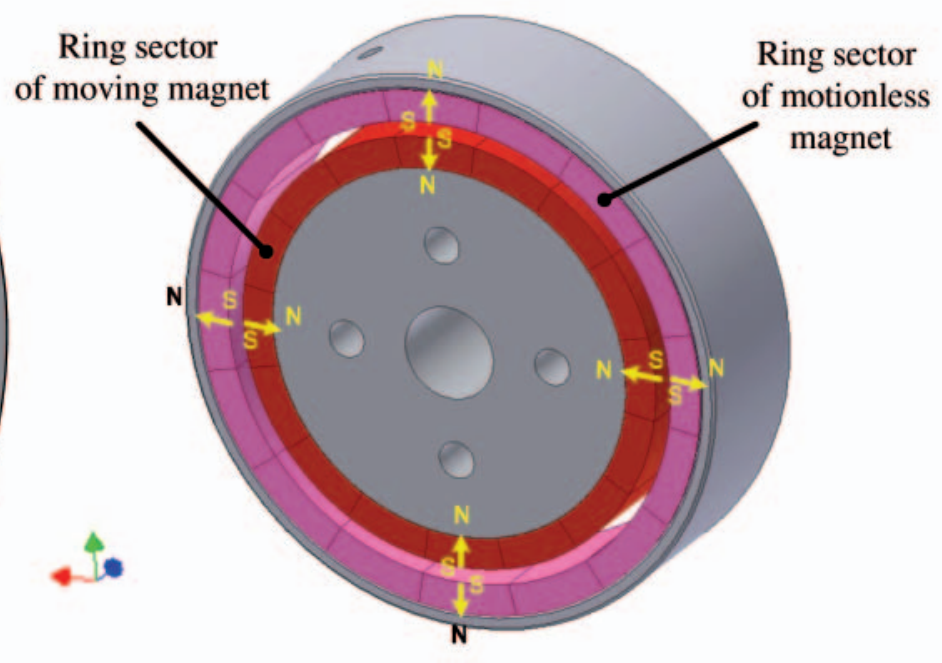

Fig. 5. Radial passive magnetic bearing 
a)

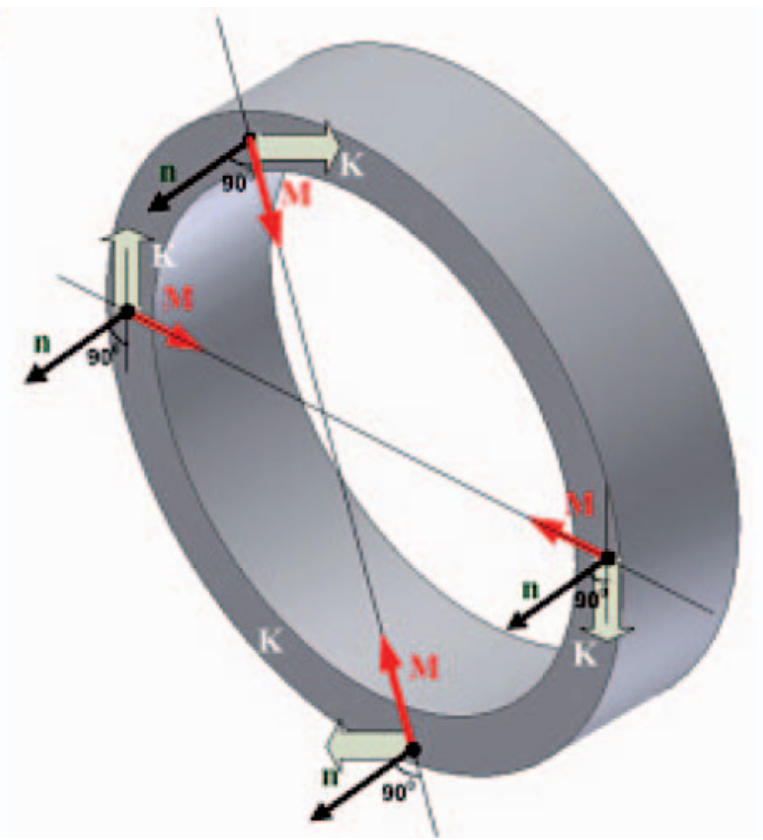

b)

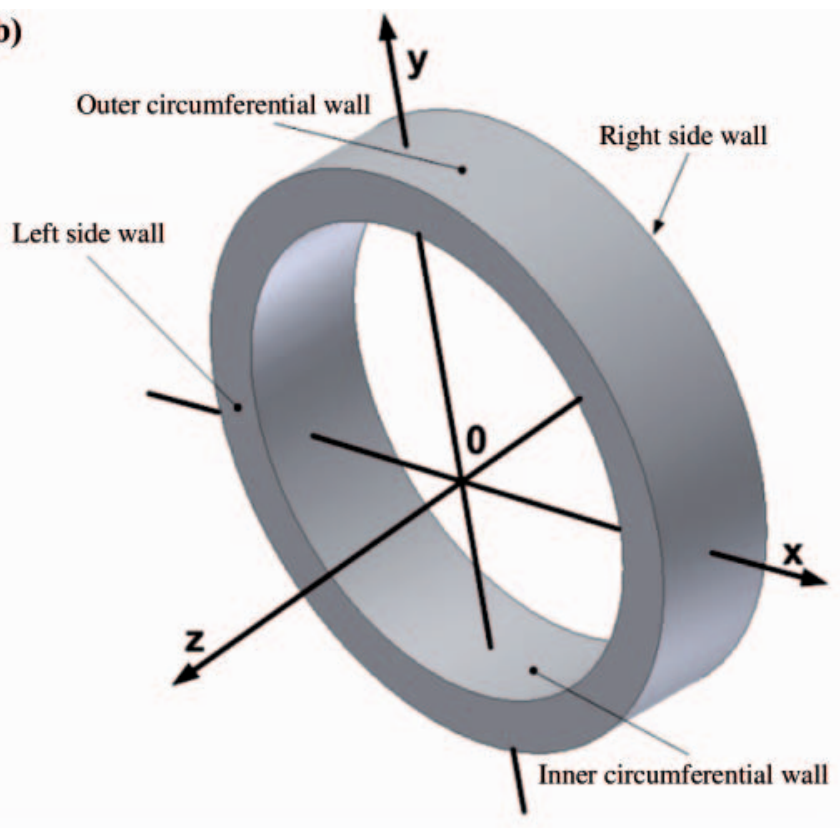

Fig. 6. Surface current constrained within side wall (6a), coordinate frame orientation in the magnet (6b)

\section{MODEL OF RADIAL PASSIVE BEARING}

Amper model was used for description of a model of magnetic interaction between two ring magnets. As assumed in the model in the magnet walls flow constrained currents being a source of magnetic field. Value of the constrained currents depends on the product of magnetization vector and that perpendicular to magnet wall [2]:

$$
\begin{gathered}
\overrightarrow{\mathrm{K}}=\overrightarrow{\mathrm{M}} \times \overrightarrow{\mathrm{n}} \\
\text { where: } \\
\overrightarrow{\mathrm{M}}-\text { magnetization vector } \\
\overrightarrow{\mathrm{n}}-\text { vector perpendicular to magnet wall. }
\end{gathered}
$$

Fig. 6 illustrates surface currents constrained within ring magnet. As results from the relation (1) the currents will occur in side walls only. They will not occur on the outer and inner circumferential walls of the magnet.

In compliance with Lorentz principle [2] the magnetic interaction force depends on the vector product of the surface constrained current and the vector of magnetic induction which penetrates the moving magnet:

$$
\overrightarrow{\mathbf{F}(\mathbf{x}, \mathbf{y}, \mathbf{z})}=\int\left(\overrightarrow{\mathbf{K}^{\prime}} \times \overrightarrow{\mathbf{B}}\right) \mathrm{d} \mathbf{a}^{\prime}
$$

$\overrightarrow{\mathrm{K}}$ - surface constrained current flowing through a given sector of the moving magnet, da'

B - vector of magnetic induction which penetrates the moving magnet sector of the surface area da' [in the point of the coordinates $(\mathrm{x}, \mathrm{y}, \mathrm{z})]$.

Fig. 6a presents the ring magnet with depicted surface currents. In the ring magnets the currents appear both in the left and right wall (Fig. 6b).

For radially magnetized ring magnet the magnetization vector is equal to [4]:

$$
\begin{gathered}
\overrightarrow{\mathbf{M}^{\prime}}=\left[\begin{array}{lll}
\mathbf{M}_{\mathrm{x}}^{\prime} & \mathrm{M}_{\mathrm{y}}^{\prime} & 0
\end{array}\right]=\left[\begin{array}{lll}
\mathrm{M}^{\prime} \cos \varphi & \mathrm{M}^{\prime} \sin \varphi & 0
\end{array}\right] \\
\text { The normal vector can be expressed as: }
\end{gathered}
$$

$$
\overrightarrow{\mathbf{n}}=\left[\begin{array}{lll}
0 & 0 & 1
\end{array}\right]
$$

The surface current in the left wall amounts to:

$$
\begin{aligned}
& \overrightarrow{\mathbf{K}_{1}^{\prime}}=\left[\begin{array}{ccc}
\overrightarrow{\mathbf{i}} & \overrightarrow{\mathbf{j}} & \overrightarrow{\mathbf{k}} \\
\mathrm{M}^{\prime} \cos \varphi^{\prime} & \mathrm{M}^{\prime} \sin \varphi^{\prime} & 0 \\
0 & 0 & 1
\end{array}\right]=\mathrm{M}^{\prime} \sin \varphi^{\prime \mathbf{i}}-\mathrm{M}^{\prime} \cos \varphi^{\prime} \mathbf{j} \\
& \overrightarrow{\mathbf{K}_{1}^{\prime}}=\left[\begin{array}{lll}
\mathrm{M}^{\prime} \sin \varphi^{\prime} & -\mathrm{M}^{\prime} \cos \varphi^{\prime} & 0
\end{array}\right]
\end{aligned}
$$


The surface current in the right wall of moving magnet is described as follows:

$$
\begin{gathered}
\overrightarrow{\mathbf{K}_{\mathbf{p}}^{\prime}}=\left[\begin{array}{ccc}
\overrightarrow{\mathbf{i}} & \overrightarrow{\mathbf{j}} & \overrightarrow{\mathbf{k}} \\
\mathrm{M}^{\prime} \cos \varphi^{\prime} & \mathrm{M}^{\prime} \sin \varphi^{\prime} & 0 \\
0 & 0 & -1
\end{array}\right]=-\mathrm{M}^{\prime} \sin \varphi^{\prime} \mathbf{i}+\mathrm{M}^{\prime} \cos \varphi^{\prime} \mathbf{j} \\
\overrightarrow{\mathbf{K}_{\mathbf{p}}^{\prime}}=\left[\begin{array}{lll}
-\mathrm{M}^{\prime} \sin \varphi^{\prime} & \mathrm{M}^{\prime} \cos \varphi^{\prime} & 0
\end{array}\right]
\end{gathered}
$$

The vector product of the surface current flowing through the left wall of moving magnet and the magnetic induction in the point of the coordinates $(\mathrm{x}, \mathrm{y}, \mathrm{z})$, is equal to:

$$
\begin{gathered}
\overrightarrow{\mathrm{K}_{1}^{\prime}} \times \overrightarrow{\mathrm{B}}=\left[\begin{array}{ccc}
\overrightarrow{\mathrm{l}} & \overrightarrow{\mathrm{j}} & \overrightarrow{\mathrm{k}} \\
\mathrm{M}^{\prime} \sin \varphi^{\prime} & -\mathrm{M}^{\prime} \cos \varphi^{\prime} & 0 \\
\mathrm{~B}_{\mathrm{x}}(\mathrm{x}, \mathrm{y}, \mathrm{z}) & \mathrm{B}_{\mathrm{y}}(\mathrm{x}, \mathrm{y}, \mathrm{z}) & \mathrm{B}_{\mathrm{z}}(\mathrm{x}, \mathrm{y}, \mathrm{z})
\end{array}\right]= \\
=-\mathrm{B}_{\mathrm{z}}(\mathrm{x}, \mathrm{y}, \mathrm{z}) \mathrm{M}^{\prime} \cos \varphi^{\prime} \overrightarrow{\mathrm{\imath}}-\mathrm{B}_{\mathrm{z}}(\mathrm{x}, \mathrm{y}, \mathrm{z}) \mathrm{M}^{\prime} \sin \varphi^{\hat{\jmath}}+\mathrm{M}^{\prime}\left(\mathrm{B}_{\mathrm{y}}(\mathrm{x}, \mathrm{y}, \mathrm{z}) \sin \varphi^{\prime}+\mathrm{B}_{\mathrm{x}}(\mathrm{x}, \mathrm{y}, \mathrm{z}) \cos \varphi^{\prime}\right) \overrightarrow{\mathrm{k}}
\end{gathered}
$$

The surface area da' of an elementary sector of magnet side wall can be estimated as follows (Fig.7):

$$
\mathrm{d} \mathbf{a}^{\prime}=\mathrm{r}^{\prime} \mathrm{d} \varphi^{\prime} \mathrm{dr} \mathrm{r}^{\prime}
$$

$\mathrm{r}^{\prime}-$ the mean radius changeable within the interval $\mathrm{r}_{1}{ }^{\prime}<\mathrm{r}^{\prime}<\mathrm{R}^{\prime}$

$\varphi^{\prime}-$ the angle changeable within the interval $0<\varphi<2 \pi$

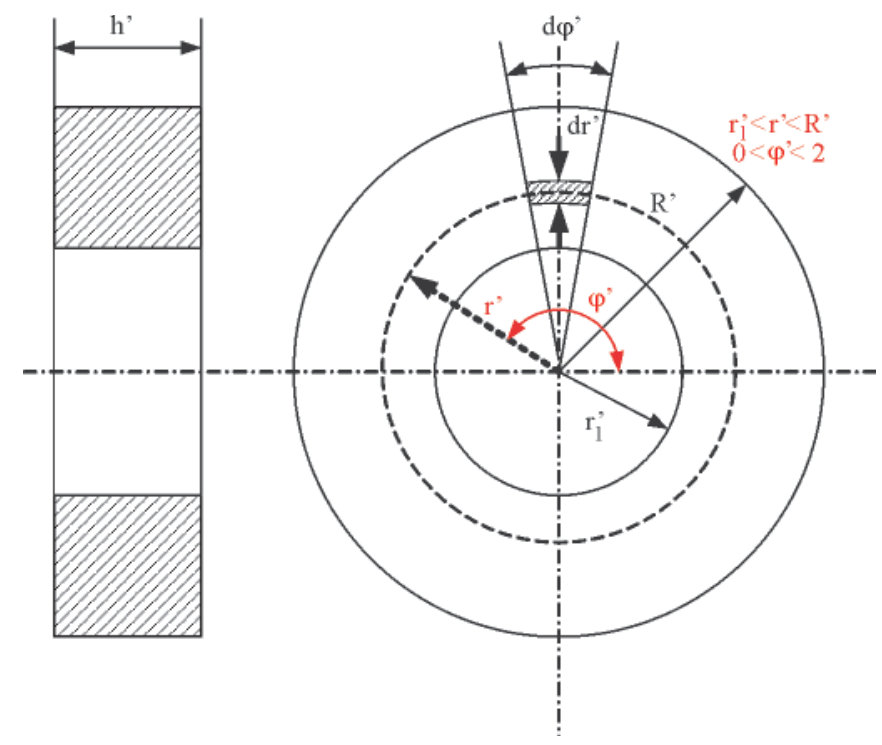

Fig. 7. The sector considered on the moving magnet side wall

By taking into account the above given relations in the Lorentz force (2) the following value of the force on the left wall is obtained:

$$
\begin{aligned}
\overrightarrow{\mathrm{F}_{\mathrm{l}}}(\mathrm{x}, \mathrm{y}, \mathrm{z})=- & \iint \mathrm{B}_{\mathrm{z}}(\mathrm{x}, \mathrm{y}, \mathrm{z}) \mathrm{M}^{\prime} \cos \varphi^{\prime} \mathrm{r}^{\prime} \mathrm{d} \varphi^{\prime} \mathrm{dr} \mathrm{r}^{\prime} \mathbf{i}-\iint \mathrm{B}_{\mathrm{z}}(\mathrm{x}, \mathrm{y}, \mathrm{z}) \mathrm{M}^{\prime} \sin \varphi^{\prime} \mathrm{r}^{\prime} \mathrm{d} \varphi^{\prime} \mathrm{dr} r^{\prime} \overrightarrow{\mathbf{j}}+ \\
& +\iint \mathrm{M}^{\prime}\left(\mathrm{B}_{\mathrm{y}}(\mathrm{x}, \mathrm{y}, \mathrm{z}) \sin \varphi^{\prime}+\mathrm{B}_{\mathrm{x}}(\mathrm{x}, \mathrm{y}, \mathrm{z}) \cos \varphi^{\prime}\right) \mathrm{r}^{\prime} \mathrm{d} \varphi^{\prime} \mathrm{dr} r^{\prime} \overrightarrow{\mathbf{k}}
\end{aligned}
$$

In the same way the magnetic force value in the points located on the moving magnet right wall, can be found:

$$
\begin{gathered}
\overrightarrow{\mathrm{F}_{\mathrm{p}}}(\mathrm{x}, \mathrm{y}, \mathrm{z})=\iint \mathrm{B}_{\mathrm{z}}(\mathrm{x}, \mathrm{y}, \mathrm{z}) \mathrm{M}^{\prime} \cos \varphi^{\prime} \mathrm{r}^{\prime} \mathrm{d} \varphi^{\prime} \mathrm{dr} \overrightarrow{\mathbf{i}} \iint \mathrm{B}_{\mathrm{z}}(\mathrm{x}, \mathrm{y}, \mathrm{z}) \mathrm{M}^{\prime} \sin \varphi^{\prime} \mathrm{r}^{\prime} \mathrm{d} \varphi^{\prime} \mathrm{d} \mathrm{r}^{\prime} \overrightarrow{\mathbf{j}}+ \\
-\iint \mathrm{M}^{\prime}\left(\mathrm{B}_{\mathrm{y}}(\mathrm{x}, \mathrm{y}, \mathrm{z}) \sin \varphi^{\prime}+\mathrm{B}_{\mathrm{x}}(\mathrm{x}, \mathrm{y}, \mathrm{z}) \cos \varphi^{\prime}\right) \mathrm{r}^{\prime} \mathrm{d} \varphi^{\prime} \mathrm{dr} \mathrm{r}^{\prime} \overrightarrow{\mathbf{k}}
\end{gathered}
$$

By using Biot-Savart principle magnetic induction in the point $p$ of the coordinates $(\mathrm{x}, \mathrm{y}, \mathrm{z})$ located in the space around motionless magnet (magnetic field source), can be determined. Points for which magnetic induction is calculated for further analysis are placed on the moving magnet. Biot-Savart principle for surface currents flowing through motionless magnets takes the following form [2]: 


$$
\overrightarrow{\mathbf{B}}(\mathbf{p})=\frac{\mu_{0}}{4 \pi} \int \frac{\mathbf{K}\left(\mathbf{p}^{\prime}\right) \times \widehat{P}}{|\overrightarrow{\mathbf{P}}|^{2}} \mathbf{d a}
$$

where:

$\widehat{\mathrm{P}}$ - versor of vector directed opposite to the surface on which surface constrained current flows to the point for which value of magnetic induction has to be determined.

The vector $\overrightarrow{\mathrm{P}}$ can be written as follows:

$$
\overrightarrow{\mathbf{P}}=|\overrightarrow{\mathbf{P}}| \widehat{\mathbf{P}}
$$

The relation can be transformed into the form:

$$
\widehat{\mathbf{P}}=\frac{\overrightarrow{\mathbf{P}}}{|\overrightarrow{\mathbf{P}}|}
$$

By accounting for Eq.(11) in Eq.(9) the relation for magnetic induction is obtained as follows:

$$
\overrightarrow{\mathbf{B}}(\mathbf{p})=\frac{\mu_{0}}{4 \pi} \int \frac{\mathbf{K}\left(\mathbf{p}^{\prime}\right) \times \overrightarrow{\mathbf{P}}}{|\overrightarrow{\mathbf{P}}|^{3}} \mathbf{d a}
$$

\begin{tabular}{|c|c|}
\hline Coordinates for the left wall, $p_{1}^{\prime}\left(x_{1}^{\prime}, y^{\prime}, z_{1}^{\prime}\right)$ & Coordinates for the right wall, $p_{p}^{\prime}\left(x_{p}^{\prime}, y_{p}^{\prime}, z_{p}^{\prime}\right)$ \\
\hline $\mathrm{x}_{1}^{\prime}=\mathrm{rcos} \varphi$ & $x_{p}^{\prime}=r \cos \varphi$ \\
\hline$y_{1}^{\prime}=r \sin \varphi$ & $y_{p}^{\prime}=r \sin \varphi$ \\
\hline $\mathrm{z}_{1}^{\prime}=\frac{\mathrm{h}}{2}$ & $\mathrm{z}_{\mathrm{p}}^{\prime}=\frac{-\mathrm{h}}{2}$ \\
\hline
\end{tabular}

Value of the magnetic induction depends on the vector $\overrightarrow{\mathrm{P}}$, therefore its coordinates between the point located on the circular loop circumference and the spatial point p' $(\mathrm{x}, \mathrm{y}, \mathrm{z})$, should be estimated. The coordinates of the point p' located on the circular loop circumference are as follows:

The coordinates of the vector $\overrightarrow{\mathrm{P}}$ for the left wall are equal to:

$$
\overrightarrow{P_{1}}=\left[\begin{array}{lll}
x-x_{1}^{\prime} & y-y_{1}^{\prime} & z-z_{1}^{\prime}
\end{array}\right]
$$

and, for the right wall, as follows:

$$
\overrightarrow{\mathrm{P}_{\mathrm{p}}}=\left[\begin{array}{lll}
\mathrm{x}-\mathrm{x}_{\mathrm{p}}^{\prime} & \mathrm{y}-\mathrm{y}_{\mathrm{p}}^{\prime} & \mathrm{z}-\mathrm{z}_{\mathrm{p}}^{\prime}
\end{array}\right]
$$

where:

$\mathrm{x}, \mathrm{y}, \mathrm{z}$ - coordinates of the point for which value of magnetic induction has to be determined.

Finally the coordinates of the vector $\overrightarrow{\mathrm{P}}$ take the form:

$$
\begin{gathered}
\overrightarrow{\mathrm{P}_{1}}=\left[\begin{array}{lll}
x-r \cos \varphi & y-r \sin \varphi & z-\frac{h}{2}
\end{array}\right] \\
\overrightarrow{\mathrm{P}_{\mathrm{p}}}=\left[\begin{array}{lll}
x-r \cos \varphi & \mathrm{y}-\mathrm{r} \sin \varphi & \mathrm{z}+\frac{\mathrm{h}}{2}
\end{array}\right] \\
\text { The module of the vector }\left|\overrightarrow{\mathrm{P}_{1}}\right| \text { takes the value: } \\
\left|\overrightarrow{\mathrm{P}_{1}}\right|=\sqrt{\mathrm{x}^{2}+\mathrm{y}^{2}+\mathrm{z}^{2}-2 r(x \cos \varphi+y \sin \varphi)-\mathrm{zh}+\mathrm{r}^{2}+\frac{\mathrm{h}^{2}}{4}} \\
\left|\overrightarrow{\mathrm{P}_{\mathrm{p}}}\right|=\sqrt{\mathrm{x}^{2}+\mathrm{y}^{2}+\mathrm{z}^{2}-2 r(x \cos \varphi+y \sin \varphi)+z h+\mathrm{r}^{2}+\frac{\mathrm{h}^{2}}{4}}
\end{gathered}
$$

For the radially magnetized ring vector the magnetization vector amounts to:

$$
\overrightarrow{\mathbf{M}}=\left[\begin{array}{lll}
\mathrm{M}_{\mathrm{x}} & \mathrm{M}_{\mathrm{y}} & 0
\end{array}\right]=\left[\begin{array}{lll}
\mathrm{M} \cos \varphi & \mathrm{M} \sin \varphi & 0
\end{array}\right]
$$

The values of surface current in the motionless magnet left and right walls are the following, respectively:

$$
\begin{aligned}
\overrightarrow{\mathbf{K}_{\mathbf{l}}} & =\left[\begin{array}{lrr}
\mathrm{M} \sin \varphi & -\mathrm{M} \cos \varphi & 0
\end{array}\right] \\
\overrightarrow{\mathbf{K}_{\mathbf{p}}} & =\left[\begin{array}{lrr}
-\mathrm{M} \sin \varphi & \mathrm{M} \cos \varphi & 0
\end{array}\right]
\end{aligned}
$$


The vector product of the surface current $\overrightarrow{\mathbf{K}_{\mathbf{l}}}$ and the vector $\overrightarrow{\mathrm{P}_{1}}$ is equal to:

$$
\overrightarrow{\mathbf{K}_{\mathbf{l}}} \times \overrightarrow{\mathbf{P}_{\mathbf{l}}}=\left[-\mathrm{M} \cos \varphi\left(\mathrm{z}-\frac{\mathrm{h}}{2}\right) \quad-\mathrm{M} \sin \varphi\left(\mathrm{z}-\frac{\mathrm{h}}{2}\right) \quad \mathrm{M}(\mathrm{x} \cos \varphi+\mathrm{y} \sin \varphi-\mathrm{r})\right]
$$

In the similar way the vector product of the surface current $\overrightarrow{\mathbf{K}_{\mathbf{p}}}$ and the vector $\overrightarrow{\mathbf{P}_{\mathbf{p}}}$ can be determined:

$$
\overrightarrow{\mathbf{K}_{\mathbf{p}}} \times \overrightarrow{\mathbf{P}_{\mathbf{p}}}=\left[\begin{array}{lll}
\mathrm{M} \cos \varphi\left(\mathrm{z}+\frac{\mathrm{h}}{2}\right) & \mathrm{M} \sin \varphi\left(\mathrm{z}+\frac{\mathrm{h}}{2}\right) & -\mathrm{M}(\mathrm{x} \cos \varphi+\mathrm{y} \sin \varphi-\mathrm{r})
\end{array}\right]
$$

For the analysis is used the magnet sector da limited by the arc of the angle $\mathrm{d} \varphi$ and the vector increment $\mathrm{dr}$. The surface area of the sector is equal to:

$$
\mathrm{d} \mathbf{a}=\mathrm{rd} \varphi \mathrm{dr}
$$

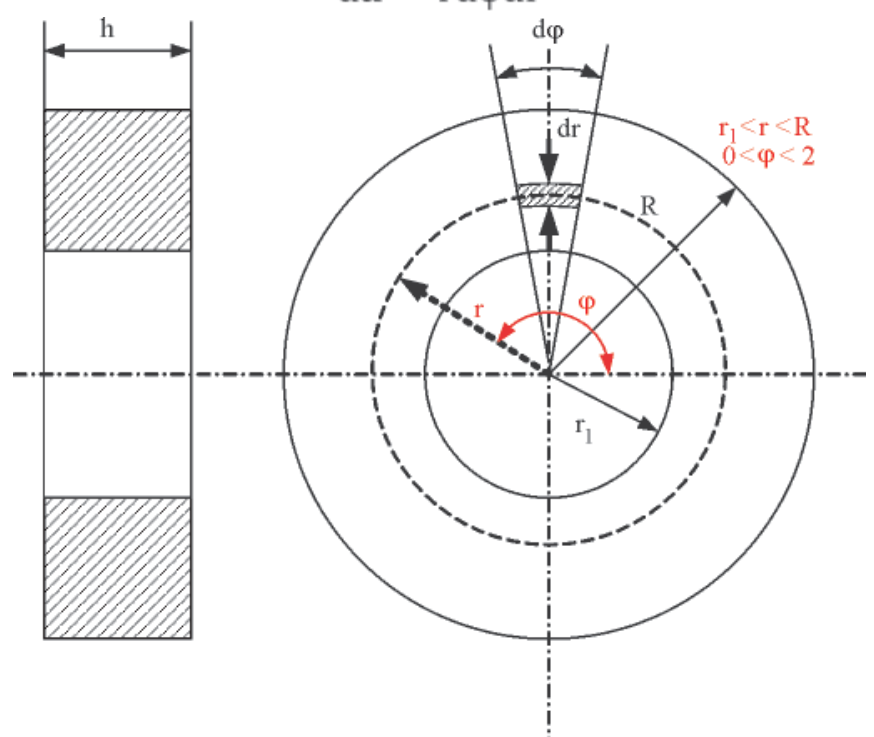

Fig. 8. The sector considered for the motionless magnet side wall

The magnetic induction value in the point $\mathrm{p}$ of the coordinates $(\mathrm{x}, \mathrm{y}, \mathrm{z})$ is equal to:

$$
\overrightarrow{\mathrm{B}}(\mathrm{x}, \mathrm{y}, \mathrm{z})=\frac{\mu_{0}}{4 \pi}\left\{\int \frac{\overrightarrow{\mathrm{K}_{1}} \times \overrightarrow{\mathrm{P}_{1}}}{\left|\overrightarrow{\mathbf{P}_{\mathbf{1}}}\right|^{3}} \mathrm{~d} \mathbf{a}+\int \frac{\overrightarrow{\mathrm{K}_{\mathrm{p}}} \times \overrightarrow{\mathrm{P}_{\mathrm{p}}}}{\left|\overrightarrow{\mathrm{P}_{\mathrm{p}}}\right|^{3}} \mathrm{da}\right\}
$$

By taking into (17) account the relations (13), (14), (15) and (16) the following magnetic induction value can be obtained:

$$
\begin{gathered}
\vec{B}(x, y, z)=\frac{\mu_{0}}{4 \pi}\left\{\left(C_{11}+C_{21}\right) \overrightarrow{\mathbf{i}}+\left(C_{12}+C_{22}\right) \overrightarrow{\mathbf{j}}+\left(C_{13}+C_{23}\right) \overrightarrow{\mathbf{k}}\right\} \\
\vec{B}(x, y, z)=\left[\begin{array}{lll}
B_{x} & B_{y} & B_{z}
\end{array}\right] \\
C_{11}=\iint \frac{\text { where: }}{\left(x^{2}+y^{2}+z^{2}-2 r(x \cos \varphi+y \sin \varphi)-z h+r^{2}+\frac{h^{2}}{4}\right)^{\frac{3}{2}}} d \varphi d r \\
C_{12}=\iint \frac{-M \sin \varphi\left(z-\frac{h}{2}\right) r}{\left(x^{2}+y^{2}+z^{2}-2 r(x \cos \varphi+y \sin \varphi)-z h+r^{2}+\frac{h^{2}}{4}\right)^{\frac{3}{2}}} d \varphi d r \\
C_{13}=\iint \frac{M(x \cos \varphi+y \sin \varphi-r) r}{\left(x^{2}+y^{2}+z^{2}-2 r(x \cos \varphi+y \sin \varphi)-z h+r^{2}+\frac{h^{2}}{4}\right)^{\frac{3}{2}}} d \varphi d r
\end{gathered}
$$




$$
\begin{aligned}
& C_{21}=\iint \frac{\operatorname{Mcos} \varphi\left(z+\frac{h}{2}\right) r}{\left(x^{2}+y^{2}+z^{2}-2 r(x \cos \varphi+y \sin \varphi)+z h+r^{2}+\frac{h^{2}}{4}\right)^{\frac{3}{2}}} d \varphi d r \\
& C_{22}=\iint \frac{M \sin \varphi\left(z+\frac{h}{2}\right) r}{\left(x^{2}+y^{2}+z^{2}-2 r(x \cos \varphi+y \sin \varphi)+z h+r^{2}+\frac{h^{2}}{4}\right)^{\frac{3}{2}}} d \varphi d r \\
& C_{23}=\iint \frac{-M(x \cos \varphi+y \sin \varphi-r) r}{\left(x^{2}+y^{2}+z^{2}-2 r(x \cos \varphi+y \sin \varphi)+z h+r^{2}+\frac{h^{2}}{4}\right)^{\frac{3}{2}}} d \varphi d r
\end{aligned}
$$

By solving the above given integrals and accounting for magnetic induction values in Lorentz force it is possible to determine lifting force of the bearing.

\section{SUMMARY}

- The elaborated mathematical model makes it possible to assess magnetic force value and direction. Such model is necessary for determination of maximum magnetic force generated by radial passive magnetic bearing. Moreover the model can be applied to assessing dynamic parameters of active magnetic suspension.

- The presented approach leads to analytical solutions which make analyzing magnetic bearings by means of mathematical programs in a simple way, possible. The model has been adjusted to the Matlab-Simulink engineering software which enables analyzing dynamic processes.

- The software based on the finite elements method (FEM), commonly used for solving static magnetic fields and magnetic forces do not make it possible to perform a comprehensive dynamic analysis of radial passive magnetic bearing.

- Basing on the elaborated model these authors conduct, by means of Matlab software, design process of passive suspensions applicable to water propellers. The elaborated models and relevant design algorithms will be verified during experimental tests and analyses with the use of FEM-based programs (static analyses).

- Elaboration of comprehensive mathematical models and then determination of their allowable simplification would make it possible to build algorithms capable of facilitating implementation of passive magnetic suspensions in practice.

- Apart from the elaboration of passive models of radial magnetic bearing, it is intended to elaborate models of axial bearings. Such bearings will be applicable to a bearing system of water propeller rotor, based on another configuration of magnetic bearings.

\section{BIBLIOGRAPHY:}

1. ISO14839-2:2004 Standard: Mechanical vibration -Vibration of rotating machinery equipped with active magnetic bearings. Part 2: Evaluation of vibration. Edition: 1 | Stage: 90.93 | TC 108/SC 2 ICS: 17.160

2. D. Griffiths: Introduction to Electrodynamics. Prince Hall, Upper Saddle River, New Jersey 07458, USA, 1999

3. Gosiewski Z., Falkowski K.: Multifunctional magnetic bearings. Monograph. Wydawnictwo Naukowe Instytutu Lotnictwa (Scientific Publishing House of Aviation Institute), Warsaw, 2003

4. Falkowski K.: Modelling passive magnetic bearings (in Polish). The Conference Automaticon 2006, Warsaw, March 2006

5. Falkowski K., Gosiewski Z.: Analytical Method of the Magnetic Forces Estimation in Passive Magnetic Bearings. The $8^{\text {th }}$ International Conference on Motion and Vibration - Control MOVIC 2006, Korea, September 2006

6. Falkowski K.: Passive magnetic bearing (in Polish). The Conference Automaticon 2007, electronically edited proceedings, Warsaw, March 2007

7. Falkowski K., Gosiewski Z.: The differential passive magnetic bearing for high-speed flexible rotor. The $3^{\text {rd }}$ International Conference on Mechatronic Systems and Materials (MSM 2007), 27 - 29 September, 2007, Kaunas, Lithuania, Published in the Solid State Phenomena Journal, Special topic volume on Mechatronic Systems and Materials II, Vol. 144, 2009.

8. Jarzyna H., Koronowicz T., Szantyr J.,A.: Design of Marine Propellers. Maszyny Przepływowe, vol.20, Ossolineum 1996.

\section{CONTACT WITH THE AUTHORS}

Leszek Matuszewski, Ph. D.

Faculty of Ocean Engineering and Ship Technology

Gdansk University of Technology Narutowicza $11 / 12$

80-233 Gdansk, POLAND e-mail: leszekma@pg.gda.pl

Krzysztof Falkowski, Ph. D. Faculty of Mechatronics,

Military University of Technology

Gen. Sylwestra Kaliskiego 2

00-908 Warsaw 49, POLAND

e-mail: krzysztof.falkowski@wat.edu.pl 